\title{
A Closer Look At Closure Scepticism
}

\author{
Michael Blome-Tillmann
}

\section{Simple Closure, Scepticism and Compe- tent Deduction}

The most prominent arguments for scepticism in modern epistemology employ closure principles of some kind. To begin my discussion of such arguments, consider Simple Knowledge Closure (SKC):

$$
(\mathrm{SKC})(K x t[p] \wedge \square(p \rightarrow q)) \rightarrow K x t[q] .^{1}
$$

Assuming its truth for the time being, the sceptic can use (SKC) to reason from the two assumptions that, firstly, we don't know $\neg s h$ and that, secondly, op entails $\neg s h$ to the conclusion that we don't know $o p$, where ' $o p$ ' and 'sh' are shorthand for 'ordinary proposition' and 'sceptical hypothesis' respectively.

(SKC), however, fails for familiar reasons: since knowledge entails belief $(\mathrm{KB})$, we can derive the falsity $(\mathrm{F})$ from (SKC) by hypothetical syllogism, and thus reduce (SKC) to absurdity:

$(\mathrm{KB}) \operatorname{Kxt}[p] \rightarrow B x t[p]$.

(F) $(K x t[p] \wedge \square(p \rightarrow q)) \rightarrow B x t[q]$.

(F) can be counterexampled easily: even though I know that the Peano Postulates are true I don't believe every theorem of arithmetic. (F) fails because we don't believe every entailment of the propositions we know. ${ }^{2}$

The sceptic might try to fix her argument by inserting an additional $K$-operator into the second conjunct of the antecedent of (SKC). Here is Known Entailment Closure (KEC):

$$
(\mathrm{KEC})(K x t[p] \wedge K x t[(p \rightarrow q)]) \rightarrow K x t[q] .^{3}
$$

\footnotetext{
${ }^{1}$ The box (' $\square$ ') denotes conceptual necessity and ensures the epistemic accessibility of the entailment.

${ }^{2}$ (Stalnaker 1996) and (Lewis 1986) would object here, since they individuate propositions in terms of possible worlds. I shall not discuss their views in this paper.

${ }^{3}$ The box is irrelevant here. The epistemic accessibility of the material conditional is established by the fact that $K x t[(p \rightarrow q)]$.
} 
However, knowledge isn't closed under known entailment either; (KEC) fails for reasons related to the reasons for (SKC)'s failure: by hypothetical syllogism we can derive (F') from (KEC) and (KB):

$\left(\mathrm{F}^{\prime}\right)(K x t[p] \wedge K x t[(p \rightarrow q)]) \rightarrow \operatorname{Bxt}[q]$.

Here is a counterexample to (F'): Norman knows both the Peano Postulates and that the Peano Postulates entail $p$, a fairly complex arithmetical proposition. However, Norman doesn't believe $p$ itself, since he fails to draw the conclusions from the propositions he knows. In short, Norman has not come to believe $p$ by deducing it from the Peano Postulates.

Even though (SKC) and (KEC) fail, it is hardly questionable that we can extend our knowledge by deductive reasoning. In the literature, principles of the following kind are usually taken to capture this intuition without becoming subject to the above objections:

(CDC) $(K x t[p] \wedge x$ believes $q$ by competently deducing it from $p) \rightarrow$ $K x t[q]{ }^{4}$

(CDC) - Competent Deduction Closure - ensures that $x$ puts her pieces of knowledge together in the right way: she comes to believe $q$ by competently deducing it from $p$. Assuming for the time being that this principle accounts for the acquisition of knowledge by deductive reasoning, we certainly don't want to do epistemology without it. ${ }^{5}$

However, even though valid, note that (CDC) is worthless for the sceptic, who intends to infer the negation of the first conjunct of the antecedent of (CDC). To this end, besides the negation of (CDC)'s consequent, the sceptic has to assume the second conjunct of (CDC)'s antecedent, which is impossible: in everyday life we don't competently deduce the negations of sceptical hypotheses from the ordinary propositions we believe. For instance, we don't normally reason that the proposition that we have had scrambled eggs for breakfast entails that we aren't brains in vats. We cannot even be said to tacitly perform cognitive operations similar to competent deductions of this sort. In everyday life we presuppose rather than reason that we aren't brains in vats.

The closure sceptic faces a difficult task: she has to find a closure principle satisfying two constraints working against each other. Firstly, to ensure the principle's exploitability in sceptical arguments, it must impose weaker restrictions on the subject's cognition than (CDC). I shall call this constraint the Exploitability Constraint. Secondly, to ensure the principle's validity, it must impose stronger restrictions on the subject's cognition than (SKC) and (KEC). I shall call this constraint the Validity Constraint.

\footnotetext{
${ }^{4}$ Cp. (Williamson, 2000), 117.

${ }^{5}$ (Dretske 1970) and (Nozick 1981) prominently want to. I shall later suggest an account similar to theirs.
} 
The goal of the remainder of this paper is to argue towards the conclusion that there is no principle conforming to both constraints.

\section{Some Candidates}

(Brueckner 1994) and (Cohen 1998) suggest the following qualification of (SKC), where ' $W$ ' refers to warrant, the evidence-related property, "whatever precisely it is, which makes the difference between knowledge and mere true belief." 6 Here is Simple Closure for Warrant (SWC):

$$
(\mathrm{SWC})(W B x t[p] \wedge \square(p \rightarrow q)) \rightarrow W B x t[q] .^{7}
$$

Apparently, (SWC) avoids the problems of (SKC) and (KEC), since the proposition that $W B x t[q]$ - the consequent of (SWC) - doesn't seem to entail $B x t[q]$ : (SWC) merely claims that $x$ is warranted in believing $q$, independently of whether she in fact comes to believe $q$ or not.

However, (SWC) is too strong as it stands: it violates the validity constraint, for it leads to the counterintuitive result that someone, who is warranted in believing the Peano Postulates, is also warranted in believing any theorem of arithmetic. Norman is a counterexample to (SWC): even though he is warranted in believing the Peano Postulates he isn't warranted in believing Fermat's Last Theorem.

Can we fix (SWC) by inserting a further $W$-operator into its second conjunct? Here is Warranted Entailment Closure (WEC):

$$
(\mathrm{WEC})(W B x t[p] \wedge W B x t[(p \rightarrow q)]) \rightarrow W B x t[p] .
$$

Now, even though (WEC) seems exploitable and valid, there are theorists denying that there is an evidence-related property of warrant. ${ }^{8}$ In order to convince these theorists, the sceptic might choose to find another route to the sceptical conclusion.

To see how this is possible, reconsider the above objection to (KEC). The problem with (KEC) was that together with (KB) it entails the falsity ( $\left.F^{\prime}\right)$. Note, however, that ( $\left.F^{\prime}\right)$ is true as long as the domain of the $q$-quantifier is restricted to sentences expressing the negations of sceptical hypotheses: in everyday life we in fact believe, mostly implicitly, that we aren't in sceptical scenarios. To yield a valid closure principle we might thus simply insert the assumption that $B x t[q]$ as a further condition into

\footnotetext{
${ }^{6}$ (Merricks 1995), 841; See also (Plantinga 1993), 3.

${ }^{7}$ Note that Brueckner and Cohen use the notion of justification in their sceptical arguments, assuming that justification is a necessary condition for knowledge (See Cohen (1998), 145 and 148fn and Brueckner (1994), 831). So as to fit Cohen's and Brueckner's formulations of the discussed closure principles, my objections are to be reformulated in terms of justification.

${ }^{8}$ See Williamson (2000).
} 
the antecedent of (KEC). Here is Known Entailment + Belief Closure $(\mathrm{KE}+\mathrm{BC})$ :

$$
(\mathrm{KE}+\mathrm{BC})((K x t[p] \wedge K x t[(p \rightarrow q)]) \wedge B x t[q]) \rightarrow K x t[q] .
$$

Is $(\mathrm{KE}+\mathrm{BC})$ exploitable? It surely is: the sceptic can use it to reason from the three assumptions that 1 . we don't know $\neg s h$ and that 2 . we know that $o p$ entails $\neg s h$ and that 3 . we believe $\neg s h$ to the conclusion that we don't know op.

\section{Warrant and the Genesis of True Belief}

In order to see where (WEC) and $(\mathrm{KE}+\mathrm{BC})$ go wrong, note firstly that they are - unlike (CDC) - silent on $x$ 's belief's genesis: (CDC) rules out that $x$ came to believe $q$ for the wrong reasons; (WEC) and (KE+BC) don't.

Let me firstly give a counterexample to $(\mathrm{KE}+\mathrm{BC})$. Imagine I prove some complex mathematical proposition $p$ and thereby come to know $p$. Half an hour later, after my coffee break, I prove that $p$ entails $q$, which is a mathematical proposition even more complex than $p$. Since I don't have in mind anymore what I have proven before the coffee break, I don't put my two pieces of knowledge together in the right way and therefore don't deduce $q$. The fact that I don't see the relevant connections between my beliefs is due to my limited memory and alertness; if you confronted me with either $p$ or the proposition that $p$ entails $q$ on their own, I would be able to reconstruct my proofs. However, after having proven $q$ I make a tea break. During my break I come to believe $q$ by reading in the tealeaves. Obviously, I satisfy the three conditions in the antecedent of $(\mathrm{KE}+\mathrm{BC})$, but I don't know $q$.

The reason why I don't know $q$ is because my belief $q$ is accidentally true only. However, according to a widely shared intuition-I shall call it the Gettier Intuition - knowledge is incompatible with epistemic luck, i.e. no belief that is knowledge is accidentally true. ${ }^{9}$ As a consequence, $(\mathrm{KE}+\mathrm{BC})$ is to be rejected because it doesn't rule out cases of epistemic luck.

With regard to (WEC) the situation isn't that straightforward. To see where (WEC) goes wrong, we firstly have to note that warrant entails belief. Here is the argument: According to the Gettier Intuition no belief that is accidentally true qualifies as knowledge. However, if warrant didn't entail belief, then there could be situations in which we are warranted in believing $p$ and believe $p$ for entirely arbitrary reasons, i.e. for reasons that aren't relevantly connected to our warrant. We could

\footnotetext{
${ }^{9} \mathrm{Cp}$. (Unger 1968).
} 
thus be warranted and have a belief that is accidentally true. By the definition of warrant, however, we would have knowledge in such cases, but this is incompatible with the Gettier Intuition. We thus have to reject the assumption that we can be warranted in believing something without actually believing it. ${ }^{10}$

What are the consequences of these considerations for (WEC)? Obviously, if warrant entails belief, then (WEC) will be open to objections similar to the above-mentioned objections to (KEC).

Let us return to (CDC). Does coming to believe by competent deduction suffice to rule out all cases of epistemic luck? Consider the following case: I come to believe $p$, a complex mathematical proposition, by competent deduction from a $q$ I know. During my tea break I read in the tealeaves and thereby become even more confident that $p$ : I take my tealeaves to provide strong additional evidence for $p$. After my experiences with the tealeaves I turn to the coffee ground, which surprisingly teaches me that my earlier deduction of $p$ from $q$ was unreliable. My belief $p$ is now solely based on my reading in tealeaves: even though my belief was acquired by competent deduction, it isn't based on competent deduction anymore. Now, since I believe $p$ for the wrong reasons, viz. for reasons that are only arbitrarily connected to $p$ 's truth, I clearly cease to know $p$.

Thus, if the phrase 'believes by competent deduction' in (CDC) is to be interpreted as qualifying the causal history of the relevant belief, then we have found a counter-example to (CDC). If, however, it is meant to qualify what causally sustains the relevant belief, then (CDC) is acceptable. How are we to amend (CDC) in order to dispose of this ambiguity? Since a belief can be adopted for one reason but later maintained for another, we are looking for constraints on the factors causally sustaining $x$ 's belief $q$ rather than for constraints on its genesis. Here is Proper Basing Closure (PBC):

(PBC) $(K x t[p] \wedge x$ believes $q$ on the basis of her competently deducing it from $p) \rightarrow K x t[q]$.

Is (PBC) exploitable? It clearly has the same problem as (CDC): in everyday life we don't base our belief that $\neg s h$ on competent deductions from op.

\footnotetext{
${ }^{10}$ The argument here assumes that warrant isn't a conjunctive property, one conjunct being the conditional that if $x$ believes $p$, her belief isn't accidentally true. Note that if the notion of accidental truth at issue here cannot be cashed out in nonepistemic terms, then warrant is ultimately to be defined in terms of knowledge, and any definition of knowledge will be circular.
} 


\section{Modal Closure}

Even though none of the above principles is both valid and exploitable, there are modal versions of closure that seem to satisfy both constraints. After all it looks as if $x$ can come to know a $q$ that is conceptually entailed by a $p$ she knows, viz. by basing her belief $q$ on a competent deduction of $q$ from $p$. Here is Modal Closure (MC):

$$
(\mathrm{MC})(K x t[p] \wedge K x t[(p \rightarrow q)]) \rightarrow \diamond(K x t[q])^{11}
$$

Clearly, this principle is exploitable: the sceptic simply has to establish that it is impossible to know - and thus impossible to come to know - the negations of sceptical hypotheses, which has been part of her argument anyway.

However, something seems wrong with (MC). To see what, consider the following pairs of propositions:

1. OP: The animals in the pen are zebras.

$S H$ : The animals are cleverly painted mules. ${ }^{12}$

2. OP: I will go to Spain for holidays next summer.

$S H$ : I will die in a horrible car crash meanwhile.

3. OP: I've had scrambled eggs for breakfast.

$S H$ : I'm a brain in a vat.

According to what I shall call 'Dretske's Intuition', these pairs of propositions constitute counterexamples to (MC): we can't come to know the negations of the above $s h$-propositions by competently deducing them from their corresponding $o p$-propositions. ${ }^{13}$ Are we to reject Dretske's Intuition or are we to reject (MC)? Even though the common reaction is to reject our intuitions, I take it that we should reject (MC) and replace it with a more intuitive principle.

To see why this is more attractive, we need to take a closer look at the above counterexamples. What do the above cases have in common? Firstly, note that those situations in which the above pairs of propositions constitute counterexamples to (MC) are situations in which all $s h$-world are - to borrow Lewis's terminology - uneliminated. What precisely does it mean for a world to be uneliminated? As Lewis puts it, a world $W$ is uneliminated "iff the subject's perceptual experience and

\footnotetext{
${ }^{11}$ I take the expression ' $\diamond(K x t[q])$ ' to mean that $x$ can come to know $q$ at $t$. The $K$ operator in the second conjunct of the antecedent ensures the impossibility of knowing undecidable propositions, such as the Continuum Hypothesis. Thanks to Alexander Bird here.

${ }^{12}$ See (Dretske 1970) for this example.

${ }^{13}$ I should mention here that some Mooreans don't seem to have this intuition.
} 
memory in $W$ exactly match his perceptual experience and memory in actuality." 14 Now, since our perceptual experiences and memory in shworlds exactly match our experiences and memory in the actual world, sh-worlds are uneliminated for us. Our epistemic stance towards the above $\neg s h$-propositions in counterexample-situations to (MC) can thus be depicted as in Figure 1, where 'SH' denotes the set of all $s h$-worlds and ' $\mathrm{E}$ ' the set of all worlds eliminated by our experience and memory:

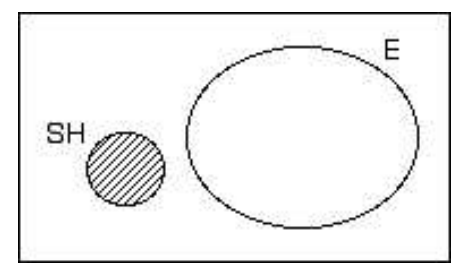

Figure 1: Epistemic situation towards $\neg s h$

In the standard situation, none of the counterpossibilities to $\neg s h$, i.e. none of the $s h$-worlds, is eliminated by our sensory experiences or memory. Thus, Dretske's Intuition has it that (MC) fails in precisely those situations, in which all counterpossibilities to the entailed proposition $q$ are uneliminated. In set-theoretic parlance, (MC) fails if $\neg Q$, i.e. the set of all $\neg q$-worlds, and $E$ are disjoint sets, i.e. if their intersection is equivalent to the empty set: $\neg Q \cap E \equiv \emptyset$.

The solution to our problem is now easily obtained. Here is Revised Modal Closure (RMC):

$$
(\mathrm{RMC})((K x t[p] \wedge K x t[(p \rightarrow q)]) \wedge \neg Q \cap E \not \equiv \emptyset) \rightarrow \diamond(K x t[q]) .
$$

According to (RMC), $x$ can come to know $q$ at $t$, if, firstly, $x$ knows $p$ at $t$, if, secondly, $p$ entails $q$ and, if, thirdly, it is not the case that all counterpossibilities to $q$ are uneliminated by $x$ 's sensory experiences and her memory.

The advantages of this principle are obvious: it allows us to extend our knowledge by deduction in the good cases, and fails to do so in the bad ones, which in turn entails the failure of sceptical arguments. Let me illustrate how it allows for the extension of knowledge in a good case: I know that the animal in the tree is a robin. It's being a robin entails that it's not a jay. If the animal were a jay, I would have different sensory experiences: robins have a reddish breast, jays don't. Since I have seen that the bird in the tree has a reddish breast, my sensory experiences eliminate nearby worlds in which the animal is a jay. It follows from (RMC) that I am in a position to know that the animal is not a jay. To be precise, I can come to know that the animal is not a jay by basing my

\footnotetext{
${ }^{14}$ Lewis 1996, 224.
} 
belief that it's not a jay on my competent deduction of that proposition from the proposition that it's a robin.

(RMC) can also account for the extension of knowledge in mathematics and logic: since mathematical and logical truths are necessary, there are no counterpossibilities to such truths, and so there are no counterpossibilities, which our experiences and memory could fail to eliminate. Thus, in the realm of mathematics and logic, all competent deductions from knowledge yield knowledge. If I am right, we have thus found a way to reconcile Dretske's anti-closure intuitions with the intuition that we can extend knowledge by deduction, while simultaneously blocking arguments for scepticism.

Let me sum up. In the first two parts of the paper I have discussed several closure principles and argued that neither of them conforms to both the exploitability constraint and the validity constraint, part of my argument resting on my view that warrant entails belief. In the third part I then discussed a modal principle, (MC), which nicely illustrated a general problem of the idea of knowledge-closure: all closure principles are open to objections based on what I called Dretske's Intuition. In reply to this challenge I have suggested to restrict (MC) along the lines of (RMC) rather than dropping the idea of closure totally or - as the Mooreans do-biting the bullet and rejecting Dretske's Intuition. The view I want to suggest is accordingly a middle way between the unqualified acceptance of closure and its unqualified rejection. ${ }^{15}$

\section{References}

[1] Brueckner, A. (1994). "The Structure of the Skeptical Argument." Philosophy and Phenomenological Research 54:827-835.

[2] Cohen, S. (1998). "Two Kinds of Skeptical Argument." Philosophy and Phenomenological Research 58:143-159.

[3] DeRose, K. (1995). "Solving the Skeptical Problem." The Philosophical Review 104: 1-52.

[4] Dretske, F. (1970). "Epistemic Operators." The Journal of Philosophy 67:1007-1023.

[5] Lewis, D. (1986). On the Plurality of Worlds. Oxford, Blackwell.

\footnotetext{
${ }^{15}$ Earlier versions of this paper have been given at the Institut Jean Nicod in Paris, the Ockham Society in Oxford, the Joint Session of the Aristotelian and Mind Society in Manchester 2005 and at ECAP5 in Lisbon. I am grateful to the audiences at these occasions. I am especially indebted, however, to Dorothy Edgington and Tim Williamson.
} 
[6] Merricks, T. (1995). "Warrant Entails Truth." Philosophy and Phenomenological Research 55:841-855.

[7] Nozick, R. (1981). Philosophical Explanations. Cambridge, Mass., Harvard UP.

[8] Plantinga, A. (1993). Warrant: The Current Debate. Oxford, OUP.

[9] Stalnaker, R. (1996). "On What Possible Worlds could not be." Morton and Stich (eds.), Benacerraf and his Critics. Oxford, Blackwell.

[10] Unger, P. (1968). "An Analysis of Factual Knowledge." The Journal of Philosophy 65:157-170.

[11] Williamson, T. (2000). Knowledge and Its Limits. Oxford, OUP. 